\title{
Iron release from the siderophore pyoverdine in Pseudomonas aeruginosa involves three new actors FpvC, FpvG and FpvH
}

\author{
Géraldine Ganne ${ }^{1,2, \#}$, Karl Brillet ${ }^{1,2, \#}$, Beata Basta ${ }^{1,2}$, Béatrice Roche ${ }^{1,2}$, Françoise Hoegy ${ }^{1,2}$, \\ Véronique Gasser ${ }^{1,2}$, Isabelle J. Schalk ${ }^{1,2, *}$ \\ ${ }^{1}$ Université de Strasbourg, UMR7242, ESBS, Bld Sébastien Brant, \\ F-67413 Illkirch, Strasbourg, France \\ ${ }^{2}$ CNRS, UMR7242, ESBS, Bld Sébastien Brant, \\ F-67413 Illkirch, Strasbourg, France \\ ${ }^{\#}$ Contributed equally to the manuscript \\ ${ }^{*}$ To whom correspondence should be addressed: Isabelle J. Schalk, UMR 7242, ESBS, Blvd \\ Sébastien Brant, BP 10412, F-67413 Illkirch, Strasbourg, France. Tel: 333688547 19; Fax: \\ 333688548 29; E-mail: isabelle.schalk@,unistra.fr.
}




\begin{abstract}
Siderophores are iron chelators produced by bacteria to access iron, an essential nutriment. Pyoverdine (PVDI), the major siderophore produced by Pseudomonas aeruginosa PAO1, consists of a fluorescent chromophore linked to an octapeptide. The ferric-form of PVDI is transported from the extracellular environment into the periplasm by the outer membrane transporter, FpvA. Iron is then released from the siderophore in the periplasm by a mechanism that does not involve chemical modification of the chelator, but an iron reduction step. Here, we followed the kinetics of iron release from PVDI, in vitro and in living cells, by monitoring its fluorescence (as apo PVDI is fluorescent whereas PVDI-Fe(III) is not). Deletion of the inner membrane proteins $f p v G$ (PA2403) and $f p v H$ (PA2404) affected ${ }^{55} \mathrm{Fe}$ uptake via PVDI and completely abolished PVDI-Fe dissociation, indicating that these two proteins are involved in iron acquisition via this siderophore. PVDI-Fe dissociation studies, using an in vitro assay, showed that iron release from this siderophore requires the presence of an iron reducer (DTT) and an iron chelator (ferrozine). In this assay, DTT could be replaced by the inner membrane protein, $\mathrm{FpvG}$, and ferrozine by the periplasmic protein, FpvC, suggesting that $\mathrm{FpvG}$ acts as a reductase and $\mathrm{FpvC}$ as an $\mathrm{Fe}^{2+}$ chelator in the process of PVDI-Fe dissociation in the periplasm of $P$. aeruginosa cells. This mechanism of iron release from PVDI is atypical among Gram-negative bacteria, but seems to be conserved among Pseudomonads.
\end{abstract}




\section{INTRODUCTION}

Pseudomonas aeruginosa, an opportunistic Gram-negative human pathogen, requires iron for its growth, as do all living organisms, because this nutrient is a co-factor for many enzymes involved in fundamental biological processes. Its intracellular concentration in $P$. aeruginosa cells has been estimated to be between $10^{-3}$ and $10^{-4} \mathrm{M} \cdot{ }^{1}$ However, iron availability in the various bacterial environments is severely limited: iron(II) is rapidly oxidized to iron(III) in the presence of oxygen, and precipitates as a polymeric oxyhydroxide. Consequently, bacteria have developed several efficient strategies for facilitating access to this essential element. One of the most commonly used strategies involves the synthesis of siderophores and their release into the bacterial environment. ${ }^{2}$ These molecules, produced by most bacteria, have various chemical structures, but have in common a low molecular weight (200 to $2000 \mathrm{Da}$ ) and an extremely high affinity for ferric iron, with, for example, $\mathrm{K}_{\mathrm{a}}$ values of $10^{43}$ and $10^{32} \mathrm{M}^{-1}$ for enterobactin and pyoverdine, respectively. ${ }^{3,4}$ All fluorescent Pseudomonas species produce and secrete specific pyoverdines as their principal siderophores. These siderophores have similar structures: a specific peptide of six to twelve amino acids (characteristic of each pseudomonad species) linked to a chromophore derived from 2,3-diamino-6,7dihydroxyquinoline, rendering the molecule both colored and fluorescent. ${ }^{5}$ Pyoverdine I (PVDI), the siderophore produced by $P$. aeruginosa PAO1, is a partially cyclic octapeptide linked to the chromophore. ${ }^{6}$ The pyoverdine pathway of $P$. aeruginosa PAO1 is the only such pathway to have been investigated at the molecular level for the biosynthesis of the siderophore and the mechanism of iron acquisition.

Siderophores chelate iron in the extracellular medium and the resulting ferricsiderophore complex is then transported back into the bacteria. This uptake always involves a specific outer membrane transporter, ${ }^{7} \mathrm{FpvAI}^{8,9}$ and $\mathrm{FpvB}^{10}$ in the case of PVDI-Fe by $P$. aeruginosa. The protonmotive force of the inner membrane drives this transport across the 
outer membrane via an inner membrane complex comprised of TonB, ExbB, and ExbD. ${ }^{11}$ Once in the periplasm, the fate of the ferric-siderophore complexes is very strain- and siderophore-specific (for a review see ${ }^{12}$ ). For example, iron dissociates from the siderophore in the periplasm for the pyoverdine ${ }^{13,14}$ and citrate ${ }^{15}$ iron uptake pathways in $P$. aeruginosa. For the ferrichrome ${ }^{16,17}$ and enterobactin ${ }^{4}$ pathways of Escherichia coli, the ferri-siderophore complexes must cross the inner membrane and iron is released from the chelator only in the bacterial cytoplasm. Bacterial ferric-siderophore dissociation mechanisms in the bacterial periplasm or cytoplasm have received little attention, and this step has been investigated for only a few siderophore pathways: the enterobactin, salmochelin, and ferrichrome pathways and their analogues. ${ }^{12}$ These studies indicate that iron is released either by hydrolysis or by modification of the siderophore scaffold, and/or by reduction of the coordinated ferric iron into ferrous iron.

For PVDI, we have previously shown that iron is released from the siderophore in the periplasm via a mechanism that does not involve chemical siderophore modification, but an apparent reduction of iron. ${ }^{13,14}$ The apo siderophore is then recycled into the extracellular medium by PvdRT-OpmQ, an ATP-dependent efflux pump. ${ }^{14,18,19}$ The cellular location of PVDI-Fe dissociation was determined using gallium $\left(\mathrm{Ga}^{3+}\right)$, a metal that cannot be removed from PVDI by reduction ( $\mathrm{Ga}$ is found primarily in the +3 oxidation state and cannot be reduced into $\mathrm{Ga}^{2+}$ ). PVDI-Ga was taken up by P. aeruginosa, but no dissociation occurred, and PVDI-Ga accumulated in the periplasm, suggesting that metal release from PVDI occurs in this cell compartment. ${ }^{13,14}$ The proteins and the precise mechanism involved in iron reduction and release from PVDI have not yet been identified.

Here, we investigated the involvement of the PA2403-10 genes ( $f p v G H J K C D E F$, Figure 1A) in iron release from PVDI in P. aeruginosa periplasm. The mutation of PA2403 and PA2404 (coding for FpvG and FpvH, respectively) completely abolished PVDI-Fe 
dissociation, substantially decreasing the cytoplasmic assimilation of ${ }^{55} \mathrm{Fe}$ via PVDI in $P$. aeruginosa cells. Moreover, in vitro, the inner membrane protein FpvG acted as an iron reductase and the periplasmic binding protein $\mathrm{FpvC}$ as an iron chelator in the mechanism of iron release from PVDI. Altogether, these combined in vivo and in vitro data highlight the key roles for the periplasmic protein FpvC and the inner membrane proteins $\mathrm{FpvG}$ and $\mathrm{FpvH}$ in the process of iron release from PVDI in P. aeruginosa cells. 


\section{RESULTS \& DISCUSSION}

fpvGHJK genes characteristics. All genes involved in the PVDI pathway are found in the same locus of the $P$. aeruginosa genome and their biological functions have been identified for many of them but the PA2403-06 genes. The PA2403-06 sequence is separated by 31pb from the PA2407-10 operon (Figure 1A and http://www.pseudomonas.com) coding for an ABC transporter composed of a permease, FpvE (PA2409), and an ATPase, FpvD (PA2408), with two periplasmic binding proteins, FpvC (PA2407) and FpvF (PA2410), involved in iron transport from the periplasm into the cytoplasm after its release from PVDI. ${ }^{20}$ The adjacent PA2403-06 operon of unknown function codes for four proteins: FpvG (PA2403; $45 \mathrm{kDa}$ ), FpvH (PA2404; 19.9 kDa), FpvJ (PA2405; 11.4 kDa), and FpvK (PA2406; 19.4 kDa). The $f p v G H J K$ genes may play a role in the mechanism of iron release from PVDI as they are localized next to the $f p v C D E F$ genes. The start and stop codons of the four $f p v G H J K$ genes overlap, suggesting that their expression may be coupled.

Secondary structure prediction performed by several algorithms (Phyre2, XtalPredRF, TMHMM, TMpred, and CCTOP) indicate that FpvG is an inner membrane protein composed of four transmembrane $\alpha$ helices (TM1: amino acids 12-36; TM2: amino acids 146167; TM3: amino acids 187-217; and TM4: amino acids 336-363) and two putative periplasmic domains (the first from residues 37 to 145 and the second from residues 218 to 335) (Figure 1B). The two putative periplasmic domains of FpvG have the same secondary organization and are composed of an $\alpha$ helix and four putative $\beta$ strands. Results from a FFASO3 search in PfamA27U revealed that FpvG significantly matches a transmembrane ascorbate ferric-reductase (from Arabidopsis thaliana) (score -9.640), belonging to the eukaryotic Cytochrome b561 family (transmembrane electron transport protein involved in iron reductase activities) (Su and al., 2006). However none of the bioinformatics analysis that we carried out allowed indicated that FpvG possesses a heme binding site. The secondary 
structure predictions for FpvH and FpvK suggest a similar organization with a putative transmembrane $\alpha$ helix (amino acids 21-41 for FpvH and amino acids $15-35$ for FpvK) and a potential periplasmic domain (amino acids 42-179 for FpvH and amino acids 36-186 for FpvK). A signal sequence (amino acids 1-25) was predicted by SignalP for FpvJ, suggesting periplasmic localization for this protein.

fpvGHJK deletion affects ${ }^{55}$ Fe uptake in P. aeruginosa. We assessed the ability of mutants carrying single $f p v G, f p v H, f p v J$, and $f p v K$ deletions or a simultaneous deletion of all four $f p v G H J K$ genes to transport and accumulate iron in the presence of PVDI, in a PVDI- ${ }^{55} \mathrm{Fe}$ uptake assay. The PVDI concentration was precisely controlled by performing the experiment using the PVDI-negative $P$. aeruginosa mutant $\Delta p v d F$ and its $f p v G, f p v H, f p v J$, and $f p v K$ deletion derivatives $(\Delta p v d F \Delta f p v G, \quad \Delta p v d F \Delta f p v H, \quad \Delta p v d F \Delta f p v J, \quad \Delta p v d F \Delta f p v K \quad$ and $\Delta p v d F \Delta f p v G H J K)$. As a negative control, we also used the $\Delta p v d F \Delta f p v A$ strain carrying the deletion of the outer membrane transporter FpvA as a negative control. We incubated bacteria in the presence of $200 \mathrm{nM}$ PVDI- ${ }^{55} \mathrm{Fe}$ and monitored the radioactivity incorporated into the cells. After $30 \mathrm{~min}, 95 \mathrm{pmol}{ }^{55} \mathrm{Fe}$ was incorporated into $\Delta p v d F$ cells, whereas we observed no ${ }^{55} \mathrm{Fe}$ accumulation in the $f p v A$ deletion mutant $\Delta p v d F \Delta f p v A$ (Figure $2 \mathrm{~A}$ ) or in the $\Delta p v d F$ cells when they were incubated in the presence of $\mathrm{CCCP}$, a proton motive force inhibitor that blocks all TonB-dependent transport. ${ }^{21}$ Deletion of $f p v G$ reduced ${ }^{55} \mathrm{Fe}$ uptake by 44 and $46 \%$ in the $\Delta p v d F \Delta f p v G$ and $\Delta p v d F \Delta f p v G H J K$ strains, respectively (Figure 2A). We only observed this phenotype in a highly iron-restricted medium, such as CAA, but not in a medium such as succinate (less iron-restricted, Supplementary Figure 2). Deletion of $f p v H$ and $f p v J$ reduced ${ }^{55} \mathrm{Fe}$ uptake by 19 and $17 \%$, respectively. Finally, deletion of $f p v K$ had no effect on ${ }^{55} \mathrm{Fe}$ uptake via the PVDI pathway. In conclusion, among the deletion of the four genes $f p v G$, $f p v H, f p v J$, and $f p v K$, we observed the strongest inhibition of iron uptake (equivalent to that 
observed for the $f p v G H J K$ deletion) for the deletion of $f p v G$, suggesting a key role for this protein in the PVDI pathway; $f p v H$ and $f p v J$ also play a role, but of lower importance.

We repeated the uptake experiments in the presence of $200 \mathrm{nM}$ PVDI- ${ }^{55} \mathrm{Fe}$ and fractionated the cells after $30 \mathrm{~min}$ incubation with the siderophore-iron complex, and measured the radioactivity in each cell compartment (periplasm, cytoplasm and membranes) (Figure 2B). For the PVDI-deficient strain $\Delta p v d F$, most of ${ }^{55} \mathrm{Fe}$ was found in the cytoplasm or associated with the membrane (41 and 32\%, respectively) and only $10 \%$ in the periplasm. For the corresponding FpvA mutant $((\Delta p v d F \Delta f p v A)$, all the radioactivity remained outside the bacteria. For the strains deleted for $f p v G$ ( $\Delta p v d F \Delta f p v G$ and $\Delta p v d F \Delta f p v G H J K)$, there was twofold lower ${ }^{55} \mathrm{Fe}$ accumulation in the cytoplasm and five-fold lower association with the membranes than for $\Delta p v d F$. In parallel, there was a four to five-fold increase of ${ }^{\mathbf{5 5}} \mathrm{Fe}$ accumulation in the periplasm, suggesting that the metal is blocked in this cell compartment in the absence of FpvG.

Overall, these data indicate that FpvG, and to a lower extend FpvH and FpvJ, are involved in iron acquisition by the siderophore PVDI and play a role in a step necessary for or preceding iron translocation from the periplasm into the cytoplasm of $P$. aeruginosa by the $\mathrm{ABC}$ transporter, FpvDE, and its two periplasmic proteins, FpvC and FpvF. ${ }^{20}$

Involvement of fpvGHJK and fpvCDEF in PVDI-Fe dissociation. PVDI is a fluorescent siderophore with experimentally exploitable spectral characteristics, due to the presence of the chromophore derived from 2,3-diamino-6,7-dihydroxyquinoline. Indeed, the apo form of PVDI is fluorescent (excitation at $400 \mathrm{~nm}$, emission at $447 \mathrm{~nm}$ ), but the PVDI-Fe complex is not. $^{13,22,23}$ The release of iron from the PVDI-Fe complex can therefore be followed in real time by monitoring the fluorescence of apo PVDI in living bacteria. ${ }^{13}$ We further investigated the role of the FpvG, FpvH, FpvJ, and FpvK proteins in iron uptake by PVDI in $P$. 
aeruginosa cells, by incubating our different mutants in the presence of $120 \mathrm{nM}$ PVDI-Fe and monitoring the fluorescence of PVDI (Figure 3A). The only source of siderophore present was the PVDI-Fe complex added to the cells at the beginning of the experiment. Consistent with previous findings, ${ }^{13}$ fluorescence increased following the addition of PVDI-Fe to $\Delta p v d F$ cells (Figure 3A, green curve). This corresponds to the dissociation of PVDI-Fe (formation of fluorescent apo PVDI) in the bacterial periplasm. ${ }^{13}$ There was no increase of fluorescence in the absence of FpvA ( $\Delta p v d F \Delta f p v A$ strain, Figure 3A, gray curve), because no PVDI-Fe could be transported into the bacteria. Deletion of the $f p v G H J K$ genes almost completely inhibited (92\%) PVDI-Fe dissociation relative to the $\Delta p v d F$ mutant (Figure 3A, blue curve). The use of single deletion mutants of the $f p v G H J K$ cluster showed that the FpvG and FpvH proteins are important for the process of iron release from PVDI in P. aeruginosa cells: deletion of these two genes completely abolished PVDI-Fe dissociation as for the $f p v A$ or $f p v G H J K$ mutants (Figure 3A, red and orange curves). Complementation of these two mutations with a plasmid carrying the $f p v G$ or $f p v H$ genes, completely restored PVDI-Fe dissociation for $f p v G$ and partially for $f p v H$ (Supplementary Figure 3). For the $\Delta p v d F \Delta f p v J$ and $\Delta p v d F \Delta f p v K$ strains, we observed 57 and $74 \%$ inhibition of PVDI-Fe dissociation, indicating that the FpvJ and FpvK proteins also play a role in the dissociation of iron from PVDI, but to a lesser extent than FpvG and FpvH (Figure 3A, pink and purple curves). All four mutants of the $f p v C D E F$ operon tested $(\Delta p v d F \Delta f p v C, \Delta p v d F \Delta f p v D E, \Delta p v d F \Delta f p v F$, and $\triangle p v d F \Delta f p v C D E F)$ showed $40 \%$ inhibition of PVDI-Fe dissociation (Figure 3B).

Iron dissociation from PVD is followed by recycling of the apo siderophore into the extracellular medium via the efflux system PvdRT-OpmQ. Recycling can be followed in real time, in vivo, by monitoring the apparition of fluorescence, corresponding to apo PVDI in the extracellular medium of $P$. aeruginosa cells. As above, we incubated the different mutants in the presence of $120 \mathrm{nM}$ PVDI-Fe (Figure 3C), collected aliquots at various intervals, pelleted 
the bacteria, and measured the fluorescence at $447 \mathrm{~nm}$ in the supernatant. Extracellular fluorescence increased for the $\Delta p v d F$ cells (Figure 3C, green curve), but not for the control samples without cells (Figure 3C, black curve) or PVDI-Fe (data not shown). This increase in fluorescence is due to recycling of metal-free PVDI from the periplasm into the extracellular medium after the release of iron from PVDI in the bacteria. ${ }^{18}$ For $\Delta p v d F \Delta f p v G$ or $\Delta p v d F \Delta f p v H$, PVDI recycling was completely abolished (Figure 3C, red and orange curves), consistent with the results of the dissociation experiment. The rate of the increase of extracellular fluorescence was considerably lower for $\Delta p v d F \Delta f p v J$ and $\Delta p v d F \Delta f p v K$ (50 and $66 \%$, respectively) compared to the experiment with $\Delta p v d F$ (Figure 3C, pink and purple curves), indicating that siderophore recycling was affected to the same extent as PVDI-Fe dissociation for these mutations. Concerning the $\mathrm{ABC}$ transporter FpvDE and its two periplasmic proteins, the $\Delta p v d F \Delta f p v C, \Delta p v d F \Delta f p v D E, \triangle p v d F \Delta f p v F$, and $\triangle p v d F \Delta f p v C D E F$ mutants showed phenotypes for apo PVDI recycling that were equivalent to the kinetics of PVDI-Fe dissociation with $45 \%$ inhibition (Figure 3D).

In conclusion, these data show that FpvG and FpvH play a key role in the mechanism of iron release from the siderophore in the bacterial periplasm. In the absence of FpvG and FpvH, PVDI can no longer release iron, and consequently, apo PVDI can no longer be recycled into the extracellular medium. The inner membrane protein FpvK and the periplasmic proteins FpvJ, FpvC, and FpvF also play a role, but their deletion has a smaller effect on the rate of PVDI-Fe dissociation. Surprisingly, even the ABC transporter FpvDE, described to be involved in the transport of siderophore-free iron across the inner membrane into the cytoplasm, ${ }^{20}$ is also important for the mechanism of iron release from the siderophore. The absence of this transporter may block steps upstream of iron translocation across the cytoplasmic membrane, preventing the further transport of siderophore-free iron. 
In vitro, DTT and ferrozine promotes iron dissociation from PVDI. Iron release from siderophores in bacterial cells often involves an iron reduction step and an $\mathrm{Fe}^{2+}$ chelator, as ferric-siderophore complexes are extremely stable. ${ }^{12}$ Previous findings from our group, based on PVDI-Ga complex uptake by $P$. aeruginosa cells, showed that iron reduction is required for the dissociation of PVDI-Fe and that it occurs in the bacterial periplasm. ${ }^{13,14}$

We further investigated the molecular mechanism involved in iron release from PVDI in $P$. aeruginosa cells by studying PVDI-Fe dissociation in vitro, using the fluorescent properties of $\mathrm{PVDI}^{13}$ in the presence of DTT as the reducing agent and ferrozine as the ferrous iron chelator. Ferrozine is used as a $\mathrm{Fe}^{2+}$ chelating reagent and indicator because it forms a stable magenta-colored complex (absorption peak at $562 \mathrm{~nm}$ ) with ferrous iron. ${ }^{24}$ Incubation of PVDI-Fe in the presence of DTT led to an increase in fluorescence, corresponding to the formation of metal-free PVDI (Figure 4A, blue curve and solid line). The addition of ferrozine led to a larger increase in fluorescence (Figure 4A, purple curve with solid line), suggesting that ferrozine increases the efficiency of PVDI-Fe dissociation in the presence of DTT, probably by chelating the ferrous iron that is formed. We followed the formation of the ferrozine- $\mathrm{Fe}^{2+}$ complex by monitoring the absorbance at $562 \mathrm{~nm}$ over time (Figure 4A, purple curve with dotted line). The kinetics of the formation of the ferrozine-Fe ${ }^{2+}$ complex were similar to those for the formation of metal-free PVDI (Figure 4A). We next assessed iron release from PVDI in the presence of ascorbic acid, a compound that simultaneously acts as a reducing agent and ferrous iron chelator. Iron was released from PVDI more efficiently by ascorbic acid than DTT (Figure 4B, green curve). The addition of ferrozine increased the amount of apo PVDI formed (Figure 4B, red curve), similar to DTT.

Thus, $\mathrm{Fe}^{3+}$ can be removed from PVDI by metal reduction, and the rate of dissociation is higher in the presence of an $\mathrm{Fe}^{2+}$ chelator. Previous studies have shown that PVDI also chelates $\mathrm{Fe}^{2+}$, in addition to $\mathrm{Fe}^{3+},{ }^{25}$ suggesting that only small amounts of metal-free PVDI are 
formed in the absence of $\mathrm{Fe}^{2+}$ trapping by ferrozine or another $\mathrm{Fe}^{2+}$ chelator. In the presence of ferrozine or ascorbic acid, ferrozine- $\mathrm{Fe}^{2+}$ and ascorbic- $\mathrm{Fe}^{2+}$ complexes are formed and iron is consequently released more efficiently from PVDI. This suggests that efficient PVDI-Fe dissociation in vivo requires both $\mathrm{Fe}^{3+}$ reduction and an exchange process in which the $\mathrm{Fe}^{2+}$ formed interacts with another chelator with a higher affinity for the reduced metal than PVDI.

FpvC facilitates DTT-dependent PVDI-Fe dissociation, like ferrozine. Sequence alignments clearly showed that $\mathrm{FpvC}$ has homology with metal-binding periplasmic proteins ${ }^{20}$ and may act as the ferrous iron chelator in the mechanism of iron release from PVDI. Similar to ferrozine, the addition of purified FpvC enhanced PVDI-Fe dissociation in the presence of excess DTT (Figure 4C, green curve), certainly by chelating the ferrous iron formed. FpvC appears to be as efficient in this process as ferrozine, since $10 \mu \mathrm{M}$ of FpvC and $10 \mu \mathrm{M}$ ferrozine displayed equivalent kinetics for PVDI-Fe dissociation (Figure 4C). There was no increase in fluorescence at $447 \mathrm{~nm}$ when PVDI-Fe was incubated in the presence of FpvC, in the absence of DTT (Figure 4C, orange curve), clearly indicating that FpvC alone is unable to remove iron from PVDI. Finally, we mutated six His residues of FpvC, potentially involved in iron chelation based on sequence alignments with metal binding periplasmic proteins, into Gly (Figure 1C). This mutated FpvC protein $\left(\mathrm{FpvC}_{\mathrm{mut}}\right)$ lost the ability to activate DTTdependent PVDI-Fe dissociation (Figure 4D, green curve with dots), confirming that FpvC acts as an iron chelator in the mechanism of iron release from PVDI.

FpvG promotes PVDI-Fe dissociation, likely playing the role of a reductase. In attempts to overexpress FpvG and FpvH in E. coli, we succeeded only for FpvG. Western blot analyses of membrane preparations of BL21(DE3) carrying the plasmid pET29a $(+) f p v G \mathrm{His}_{6}$ confirmed that FpvG is a membrane protein (Figure 5). We observed no expression of FpvH. We further 
investigate the role of FpvG in the PVDI pathway, by following PVDI-Fe dissociation by fluorescence in the presence of cytoplasmic membranes isolated from E. coli strains expressing, or not, FpvG. We observed increased fluorescence, corresponding to the release of iron from PVDI, only with the membranes isolated from E. coli cells expressing FpvG (Figure 4E, red curve). There was no increase of fluorescence with membranes from E. coli cells not carrying the pET29a(+)FpvGHis ${ }_{6}$ plasmid (Figure 4E, orange curve), indicating that FpvG is responsible for the observed PVDI-Fe dissociation and no other E. coli membrane proteins. The kinetics of PVDI-Fe dissociation in the presence of FpvG were faster, with a higher plateau, than in the presence of DTT (Figure 4E, blue curve) indicating that FpvG acts like DTT as a reducer in this in vitro PVDI-Fe dissociation assay. We also extracted FpvG from the membranes by $1 \%$ DDM and purified it using a HisTrap HP column, but observed no PVDI-Fe dissociation with the purified FpvG (data not shown). The reductase activity of FpvG is likely unstable in the presence of oxygen and detergent or requires stabilization by FpvH, FpvJ, and FpvK. The ability to replace the role of DTT in in vitro PVDI-Fe dissociation assays and the absence of PVDI-Fe dissociation in a $f p v G$ mutant strongly suggest that FpvG is the reductase in the process of PVDI-Fe dissociation in $P$. aeruginosa cells. In agreement with its probable role as a reductase, results from a FFASO3 search in PfamA27U revealed that FpvG significantly matches a transmembrane ascorbate ferricreductase (from Arabidopsis thaliana) (score -9.640), belonging to the eukaryotic Cytochrome b561 family. Cytochrome b561 family members are transmembrane electron transport proteins involved in iron reductase activities and are characterized by a central transmembrane four-helix core containing four highly conserved histidine residues anchoring two heme groups (Su and al., 2006). However none of the bioinformatics analysis that we carried out indicated that FpvG possesses a heme binding site.

FpvG-promoted PVDI-Fe dissociation is not enhanced by the addition of the $\mathrm{Fe}^{2+}$ 
chelator ferrozine (Figure 4E, purple curve), suggesting that ferrous iron is not liberated into the media in the presence of FpvG. Ferrous iron may remain bound to FpvG, chelated either by the protein or in a FpvG-PVDI complex with a mixed coordination shell for iron, involving residues of FpvG and the L-formyl-N $\mathrm{N}^{\delta}$-hydroxyornithines of PVDI (the catechol group of PVDI is no longer involved in chelation, as the siderophore became fluorescent in the presence of FpvG).

This ability of FpvG to act as a reductase in in vitro PVDI-Fe dissociation assays raises many questions. Further biophysical studies will be necessary to investigate the interaction between PVDI-Fe and FpvG, the location of the siderophore binding site on FpvG, and the precise enzymatic mechanism that allows the release of iron from PVDI. Previous studies have clearly shown that PVDI-Fe dissociation in vivo involves no chemical modification or degradation of PVDI, only an iron reduction step. ${ }^{13}$ Altogether, the in vivo and in vitro data show FpvG to be the reductase in the mechanism of PVDI-Fe dissociation in $P$. aeruginosa cells. The $f p v G$ gene is conserved in most Pseudomonas species, with the exception of the non-fluorescent Pseudomonas stutzeri and Pseudomonas mendocina, suggesting that the present mechanism may be conserved among Pseudomonads.

\section{Why is the periplasmic protein FpvC unable to promote FpvG-dependent PVDI-Fe}

dissociation? The data presented in Figure 4C and 4D show that FpvC can act like ferrozine in DTT-promoted PVDI-Fe dissociation in vitro. Surprisingly, FpvC slowed down PVDI-Fe dissociation when DTT was replaced in the assay by FpvG (Figure 4F, green curve). Addition of the purified periplasmic siderophore binding protein $\mathrm{FpvF},{ }^{20}$ also slowed down the kinetics of PVDI-Fe dissociation (Figure 4F, blue curve), likely because of competition with FpvG for binding to PVDI-Fe. Finally, the addition of both FpvC and FpvF substantially reduced PVDI-Fe dissociation in the presence of FpvG (Figure 4F, orange curve). Previous in vitro 
and in vivo studies have shown that $\mathrm{FpvC}$ and $\mathrm{FpvF}$ can simultaneously interact with and bind to PVDI-Fe in a FpvC-FpvF-PVDI-Fe complex. ${ }^{20} \mathrm{FpvC}$ and FpvF likely form a FpvC-FpvF complex, which probably has a higher affinity for PVDI-Fe than FpvG, inhibiting FpvGdependent iron dissociation. Under such experimental conditions, PVDI-Fe would be scavenged by FpvC-FpvF and would be unable to interact with FpvG. Moreover, the data presented in Figures 2 and 3, show that FpvH, and to a lesser extent, FpvJ and FpvK, are also involved in iron acquisition by PVDI and may be involved in PVDI-Fe dissociation. One of these three proteins may aid the transfer of ferrous iron from FpvG to FpvC. In further studies, it will be important to investigate the precise role of each protein of the $f p v G H J K$ operon, whether they form an inner membrane complex, and how they interact with each other, as well as with the periplasmic binding proteins FpvC and FpvF.

\section{CONCLUSION}

This study improves our understanding of the mechanism implicated in the release of iron from PVDI in P. aeruginosa cells. The PVDI-Fe complex is probably first scavenged by the periplasmic FpvC-FpvF complex, as previously proposed, ${ }^{20}$ following translocation across the outer membrane from the extracellular medium into the bacterial periplasm via the TonBdependent transporter FpvA. Iron release from PVDI occurs in the bacterial periplasm and involves an iron reduction step ${ }^{13}$ and the expression of FpvG, FpvH, FpvJ, and FpvK (Figure 3). FpvG acts as an iron reductase and FpvH, FpvJ and FpvK proteins probably act as partners of FpvG, since FpvG alone is able to replace DTT in in vitro PVDI-Fe dissociation assays (Figure 4E). Iron can then be transferred to another chelator, FpvC, as PVDI has a lower affinity for ferrous than ferric iron. It is possible that $\mathrm{FpvC}$ then brings the iron ion to the $\mathrm{ABC}$ transporter FpvDE for its translocation into the cytoplasm. ${ }^{20}$ Apo PVDI is recycled into the extracellular medium by the efflux pump PvdRT-OpmQ to start a new iron uptake 
cycle. ${ }^{14,18,19}$ FpvG appears to be a reductase but requires the other proteins, FpvH, FpvJ, and FpvK, as partners. Further studies will be necessary to understand the exact enzymatic reaction carried out by FpvG, the exact roles of FpvH, FpvJ, and FpvK, and how these proteins interact and transfer iron from PVDI to FpvC. Such a periplasmic mechanism for ferric-siderophore dissociation involving the inner membrane reductase FpvG has never been described for any other iron uptake pathway in Gram-negative bacteria and is probably a specific system conserved among pyoverdine producing Pseudomonads.

\section{METHODS}

Chemicals, growth media, and siderophores. The protonophore CCCP was purchased from Sigma. ${ }^{55} \mathrm{FeCl}_{3}$ was obtained from Perkin Elmer Life and Analytical Sciences, in solution, at a concentration of $71.1 \mathrm{mM}$, with a specific activity of $10.18 \mathrm{Ci}^{-1}$. PVDI was purified as previously described. ${ }^{26}$ LB broth and LB broth agar medium were purchased from Difco and were used as nutriment-rich medium in all experiments.

Escherichia coli strains were routinely grown in LB broth at $37^{\circ} \mathrm{C}$. For cultures of $P$. aeruginosa strains in iron-limited media, bacteria were first grown in LB broth overnight at $30^{\circ} \mathrm{C}$. The bacteria were then washed in succinate medium $\left(6.0 \mathrm{~g} \mathrm{~L}^{-1} \mathrm{~K}_{2} \mathrm{HPO}_{4}, 3.0 \mathrm{~g} \mathrm{~L}^{-1}\right.$ $\mathrm{KH}_{2} \mathrm{PO}_{4}, 1.0 \mathrm{~g} \mathrm{~L}^{-1}\left[\mathrm{NH}_{4}\right]_{2} \mathrm{SO}_{4}, 0.2 \mathrm{~g} \mathrm{~L}^{-1} \mathrm{MgSO}_{4} .7 \mathrm{H}_{2} \mathrm{O}, 4.0 \mathrm{~g} \mathrm{~L}^{-1}$ sodium succinate; the $\mathrm{pH}$ was adjusted to 7.0 by the addition of $\mathrm{NaOH}$ ) or CAA medium (casamino acid medium, composition: $5 \mathrm{~g} \mathrm{~L}^{-1}$ low-iron CAA (Difco), $1.46 \mathrm{~g} \mathrm{~L}^{-1} \mathrm{~K}_{2} \mathrm{HPO}_{4} 3 \mathrm{H}_{2} \mathrm{O}, 0.25 \mathrm{~g} \mathrm{~L}^{-1} \mathrm{MgSO}_{4}$ $7 \mathrm{H}_{2} \mathrm{O}$ ) and incubated for $24 \mathrm{~h}$ at $30^{\circ} \mathrm{C}$. Afterwards, bacteria were diluted to $0.1 \mathrm{OD}_{600 \mathrm{~nm}}$ in fresh succinate or CAA medium and incubated at $30^{\circ} \mathrm{C}$ overnight. Media were supplemented as necessary with $150 \mu \mathrm{g} \mathrm{mL} \mathrm{m}^{-1}$ carbenicillin. CAA is a more highly iron restricted medium 
than succinate medium with iron concentrations of $20 \mathrm{nM}$ and $300 \mathrm{nM}$, respectively. ${ }^{1}$ The iron concentration in LB is approximately $4 \mu \mathrm{M} .^{1}$

Gene deletion mutant construction. All DNA amplifications for cloning were performed using Phusion High-Fidelity DNA polymerase (ThermoFisher Scientific) and genomic DNA of the PAO1 strain. Restriction endonucleases were purchased from ThermoFisher Scientific and T4 DNA ligase from Takara. All enzymes were used in accordance with the manufacturer's instructions. The primers used are listed in Table SM1. Escherichia coli strain TOP10 (Invitrogen) was used as the host strain for all plasmids. The deletion strategy is described in Supporting Information.

Bacterial growth kinetics. Cells were cultured overnight in $\mathrm{LB}$ medium at $37^{\circ} \mathrm{C}$, and then at $30^{\circ} \mathrm{C}$ overnight in iron-deficient succinate medium. They were then diluted to $0.1 \mathrm{OD}_{600 \mathrm{~nm}}$ units. The suspension $(200 \mu \mathrm{l})$ was dispensed into individual wells of a 96-well plate (Greiner, PS flat-bottomed microplate). Plates were incubated at $30^{\circ} \mathrm{C}$, with shaking, in a TECAN microplate reader (Infinite M200, TECAN) for measurements of $\mathrm{OD}_{600}$ at 30 minuteintervals, for $30 \mathrm{~h}$. Each growth curve represents the mean derived from five replicates.

Expression of FpvG and FpvH in E. coli and membrane preparations. To construct an overexpressing vector for C-terminal His-tagged $f p v G$ expression, a synthetic gene was synthesized by the company GenScript and cloned into the pUC57 vector. The fpvGHis 6 fragment was than cloned into the pET29a(+) plasmid using the $\mathrm{NdeI}$ and $\mathrm{XhoI}$ restriction sites, giving the pET29a(+)-fpvGHis 6 vector.

To overexpress FpvH with a His tag in the $\mathrm{N}$ or $\mathrm{C}$ terminus, DNA was amplified by PCR using two sets of primer pairs, $\mathrm{His}_{6} \mathrm{FpvH}_{1 / 2}$ and FpvHHis 6 1/2 (Supplementary Table 1), 
to obtain the $\mathrm{His}_{6} f p v H$ and $f p v H \mathrm{His}_{6}$ genes, respectively. These DNA fragments were digested by BamHI and HindIII and inserted into the pMMB190 vector, linearized with the same enzymes, to get both recombinant plasmids pMMB190His 6 fp $v H$ and pMMB190fp $v H \mathrm{His}_{6}$.

FpvG C-terminal His-tagged protein was overexpressed in E. coli BL21(DE3) cells carrying the pET29a $(+)$ FpvGHis $_{6}$ plasmid. Strains E. coli BL21(DE3)(pET29a(+)FpvGHis 6 ) and the control strain BL21(DE3)(pET29a) were used to prepare bacterial membranes containing or not FpvG. After growth in LB, bacteria were re-suspended in $50 \mathrm{mM}$ Tris- $\mathrm{HCl}$ $\mathrm{pH} 8.0$ in the presence of $1 \mathrm{mM}$ EDTA and cells were disrupted by sonication. Afterwards, unbroken cells were pelleted during $20 \mathrm{~min}$ at $6,700 \mathrm{~g}$. The supernatant was collected and membranes pelleted by centrifugation during $40 \mathrm{~min}$ at $125,000 \mathrm{~g}$ at $4^{\circ} \mathrm{C}$. The membranes were re-suspended in $50 \mathrm{mM}$ Tris- $\mathrm{HCl} \mathrm{pH} 8.0$ and the protein concentrations were determined using the BCA (Pierce) assay.

We also attempted to express FpvH in E. coli BL21(DE3) using the

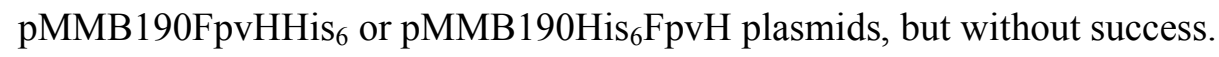

Purification of $\boldsymbol{F p v C ,} \boldsymbol{F p v} \boldsymbol{C}_{\boldsymbol{m} u t}$, and $\boldsymbol{F p v F}$. FpvC and His-tagged FpvF were purified from $E$. coli BL21(DE3) and P. aeruginosa strains respectively carrying pET23a-789 or pVEGA6 plasmids as described previously ${ }^{20}$ using the protocol detailed in the same reference.

$\mathrm{FpvC}_{\mathrm{mut}}$ is a mutant of $\mathrm{FpvC}$, with His40, His65, His110, His176, His198, and His249 mutated into Gly and a His-tag at the C-terminal end. To construct an overexpressing vector for $\mathrm{FpvC}_{\text {mut }}$ production, a synthetic gene was synthesized by the company GenScript and cloned into the pUC57 vector. The $f p v C_{m u t}$ fragment was than cloned into the pET29a(+) plasmid using the $N d e I$ and $X h o I$ restriction sites, giving the pET29a(+)-fpv $C_{m u t}$ vector. $\mathrm{FpvC}_{\text {mut }}$ was purified from E. coli BL21(DE3)(pET29a(+)-fpvC $\left.C_{m u t}\right)$ strains. E. coli cells expressing $\mathrm{FpvC}_{\mathrm{mut}}$ protein were grown in Luria Bertani (LB)-kanamycin $(100 \mu \mathrm{g} . \mathrm{ml})$ at $37^{\circ} \mathrm{C}$ 
and $220 \mathrm{rpm}$ until the optical density $\left(\mathrm{OD}_{600 \mathrm{~nm}}\right)$ of the cultured cells reached 0.6. Expression of the recombinant protein was induced with $2 \mathrm{mM}$ isopropyl- $\beta$-D-thiogalactopyranoside (IPTG) at $37^{\circ} \mathrm{C}$ during $3 \mathrm{~h}$. The cells were harvested and washed with $50 \mathrm{mM}$ Tris- $\mathrm{HCl} \mathrm{pH}$ 8.0, $1 \mathrm{mM}$ EDTA. The pellet was disurpted by sonication, and centrifuged $20 \mathrm{~min}$ at $6,700 \mathrm{~g}$ to remove unbroken cells. The supernatant was then loaded onto an HisTrap column, the $\mathrm{FpvC}_{\text {mut }}$ protein was eluted with a linear imidazole gradient. The fractions containing $\mathrm{FpvC}_{\mathrm{mut}}$ were analyzed on a SDS-PAGE gel and then purified onto a Superdex 200 10/300 GL column, equilibrated with $50 \mathrm{mM}$ Tris- $\mathrm{HCl}, \mathrm{NaCl} 300 \mathrm{mM}$ pH 8.0, to remove aggregates. After purification, all the protein fractions were pooled and concentrated by ultrafiltration at 10,000 g using a 10,000 kDa molecular weight cut off (Amicon, Millipore).

Iron uptake assays and cell fractionation. The PVDI- ${ }^{55} \mathrm{Fe}$ complex was prepared at ${ }^{55} \mathrm{Fe}$ concentrations of $20 \mu \mathrm{M}$, with a siderophore:iron (mol:mol) ratio of 20:1. Bacteria were grown in CAA medium as described above, then washed with $50 \mathrm{mM}$ Tris- $\mathrm{HCl} \mathrm{pH} 8.0$, and diluted to an $\mathrm{OD}_{600 \mathrm{~nm}}$ of 1 . Transport assays were initiated by adding $200 \mathrm{nM}$ PVDI- ${ }^{55} \mathrm{Fe}$ to the bacteria. The incorporation of radioactivity into the bacteria was monitored immediately after addition of PVDI- ${ }^{55} \mathrm{Fe}$ and after 15 and 30 min incubation, by centrifugation, as previously described. ${ }^{27}$ The experiments were repeated with cells pretreated with $200 \mu \mathrm{M}$ CCCP. This compound inhibits the proton-motive force across the bacterial cell membranes, inhibiting TonB-dependent iron uptake. ${ }^{21}$

For the cell fractionation assay, $25 \mathrm{~mL}$ bacterial grown in CAA medium were incubated in the presence of $200 \mathrm{nM}$ PVDI- ${ }^{55} \mathrm{Fe}$ at $30^{\circ} \mathrm{C}$. After 30 min incubation, periplasmic, cytoplasmic and membrane fractions were isolated as previously described. ${ }^{28}$

Fluorescence spectroscopy (PVDI-Fe dissociation and PVDI recycling experiments). All 
measurements were performed using a TECAN microplate reader (Infinite M200, TECAN) for all in vivo and in vitro assays. Samples were stirred at $30^{\circ} \mathrm{C}$ in $96-$ well plates, the excitation wavelength set to $400 \mathrm{~nm}$, and the fluorescence emission measured at $447 \mathrm{~nm}$ every $300 \mathrm{~ms}$ for the duration of the experiment.

For the in vitro PVDI-Fe dissociation experiments, PVDI-Fe was used at a concentration of $20 \mu \mathrm{M}$ in $200 \mu \mathrm{L} 100 \mathrm{mM}$ acetate ammonium buffer, $\mathrm{pH}$ 6.5. PVDI-Fe dissociation was followed at $447 \mathrm{~nm}$ in the presence or absence of either $100 \mathrm{mM}$ DTT, 100 $\mathrm{mM}$ ascorbic acid, $2 \mathrm{mM}, 200 \mu \mathrm{M}$ or $20 \mu \mathrm{M}$ ferrozine, $10 \mu \mathrm{M}$ FpvC, $10 \mu \mathrm{M}$ FpvF, and $10 \mu \mathrm{g}$ membranes.

For the in vivo PVDI-Fe dissociation experiments, cells grown in CAA or succinate media, as described above, were washed with two volumes of $50 \mathrm{mM}$ Tris- $\mathrm{HCl}, \mathrm{pH} 8.0$ and resuspended in the same buffer to a final $\mathrm{OD}_{600 \mathrm{~nm}}$ of 0.4 . PVDI-Fe was added to a concentration of $120 \mathrm{nM}$ and the fluorescence at $447 \mathrm{~nm}$ measured. As a control, the same experiments were repeated in the absence of (i) the siderophore or (ii) bacteria.

For the PVDI recycling experiments, bacteria were prepared at $\mathrm{OD}_{600 \mathrm{~nm}}$ of 1 in a volume of $3 \mathrm{~mL}$. PVDI-Fe was added to the cells to a concentration of $120 \mathrm{nM}$. $200 \mu \mathrm{L}$ of the suspension was removed at regular time intervals, the bacteria pelleted, and the fluorescence at $447 \mathrm{~nm}$ (excitation wavelength: $400 \mathrm{~nm}$ ) monitored in $150 \mu \mathrm{L}$ supernatant. As a control, the same experiments were repeated in the absence of (i) the siderophore or (ii) the bacteria.

\section{ACKNOWLEDGMENTS}

This work was partly funded by the Centre National de la Recherche Scientifique and a grant from the ANR (Agence Nationale de Recherche, IronPath ANR-12-BSV8-0007-01). B. Roche was paid by Roche Phamaceutical. 
1

2

3

4

5

6

7

10

11

12

13

14

15

16

17

18

19

20

21

22

23

24

25

26

27

28

29

30

31

32

33

34

35

36

37

38

39

40

41

42

43

44

45

46

47

48

49

50

51

52

53

54

55

56

57

58

59

60

Supporting Information Available: This material is available free of charge via the Internet. 


\section{REFERENCES}

1. Cunrath, O., Geoffroy, V. A., and Schalk, I. J. (2015) Metallome of Pseudomonas aeruginosa: a role for siderophores. Env. Microbiol. 18, 3258-3267

2. Boukhalfa, H., and Crumbliss, A. L. (2002) Chemical aspects od siderophore mediated iron transport. Biometals 15, 325-39.

3. Albrecht-Gary, A. M., Blanc, S., Rochel, N., Ocacktan, A. Z., and Abdallah, M. A. (1994) Bacterial iron transport: coordination properties of pyoverdin $\mathrm{PaA}$, a peptidic siderophore of Pseudomonas aeruginosa. Inorg Chem 33, 6391-6402.

4. Raymond, K. N., Dertz, E. A., and Kim, S. S. (2003) Enterobactin: an archetype for microbial iron transport. Proc Natl Acad Sci U A 100, 3584-8.

5. Ye, L., Ballet, S., Hildebrand, F., Laus, G., Guillemyn, K., Raes, J., Matthijs, S., Martins, J., and Cornelis, P. (2013) A combinatorial approach to the structure elucidation of a pyoverdine siderophore produced by a Pseudomonas putida isolate and the use of pyoverdine as a taxonomic marker for typing P. putida subspecies. Biometals Int. J. Role Met. Ions Biol. Biochem. Med. 26, 561-575.

6. Demange, P., Wendenbaum, S., Linget, C., Mertz, C., Cung, M. T., and Dell, A., Abdallah, M. A. (1990) Bacterial siderophores: structure and NMR assigment of pyoverdins PaA, siderophores of Pseudomonas aeruginosa ATCC 15692. Biol Met. 3, 155-170.

7. Schalk, I. J., Mislin, G. L. A., and Brillet, K. (2012) Structure, function and binding selectivity and stereoselectivity of siderophore-iron outer membrane transporters. Curr. Top. Membr. 69, 37-66.

8. Poole, K., Neshat, S., and Heinrichs, D. (1991) Pyoverdine-mediated iron transport in Pseudomonas aeruginosa: involvement of a high-molecular-mass outer membrane protein. FEMS Microbiol Lett 62, 1-5. 
9. Wirth, C., Meyer-Klaucke, W., Pattus, F., and Cobessi, D. (2007) From the periplasmic signaling domain to the extracellular face of an outer membrane signal transducer of Pseudomonas aeruginosa: crystal structure of the ferric pyoverdine outer membrane receptor. J Mol Biol 68, 398-406.

10. Ghysels, B., Dieu, B. T., Beatson, S. A., Pirnay, J. P., Ochsner, U. A., Vasil, M. L., and Cornelis, P. (2004) FpvB, an alternative type I ferripyoverdine receptor of Pseudomonas aeruginosa. Microbiology 150, 1671-80.

11. Postle, K., and Larsen, R. A. (2007) TonB-dependent energy transduction between outer and cytoplasmic membranes. Biometals 20, 453-65.

12. Schalk, I. J., and Guillon, L. (2013) Fate of ferrisiderophores after import across bacterial outer membranes: different iron release strategies are observed in the cytoplasm or periplasm depending on the siderophore pathways. Amino Acids 44, 1267-77.

13. Greenwald, J., Hoegy, F., Nader, M., Journet, L., Mislin, G. L. A., Graumann, P. L., and Schalk, I. J. (2007) Real-time FRET visualization of ferric-pyoverdine uptake in Pseudomonas aeruginosa: a role for ferrous iron. J Biol Chem 282, 2987-2995.

14. Yeterian, E., Martin, L. W., Lamont, I. L., and Schalk, I. J. (2010) An efflux pump is required for siderophore recycling by Pseudomonas aeruginosa. Env. Microbiol Rep. 2, 412 418.

15. Marshall, B., Stintzi, A., Gilmour, C., Meyer, J.-M., and Poole, K. (2009) Citratemediated iron uptake in Pseudomonas aeruginosa: involvement of the citrate-inducible FecA receptor and the FeoB ferrous iron transporter. Microbiol. Read. Engl. 155, 305-315.

16. Hartman, A., and Braun, V. (1980) Iron transport in Escherichia coli: uptake and modification of ferrichrome. J Bacteriol 143, 246-55.

17. Matzanke, B. F., Anemuller, S., Schunemann, V., Trautwein, A. X., and Hantke, K. (2004) FhuF, part of a siderophore-reductase system. Biochemistry (Mosc.) 43, 1386-92. 
18. Schalk, I. J., Abdallah, M. A., and Pattus, F. (2002) Recycling of pyoverdin on the FpvA receptor after ferric pyoverdin uptake and dissociation in Pseudomonas aeruginosa. Biochemistry (Mosc.) 41, 1663-1671.

19. Imperi, F., Tiburzi, F., and Visca, P. (2009) Molecular basis of pyoverdine siderophore recycling in Pseudomonas aeruginosa. Proc Natl Acad Sci U A 106, 20440-5.

20. Brillet, K., Ruffenach, F., Adams, H., Journet, L., Gasser, V., Hoegy, F., Guillon, L., Hannauer, M., Page, A., and Schalk, I. J. (2012) An ABC transporter with two periplasmic binding proteins involved in iron acquisition in Pseudomonas aeruginosa. ACS Chem Biol 7, $2036-45$.

21. Clément, E., Mesini, P. J., Pattus, F., Abdallah, M. A., and Schalk, I. J. (2004) The binding mechanism of pyoverdin with the outer membrane receptor FpvA in Pseudomonas aeruginosa is dependent on its iron-loaded status. Biochemistry (Mosc.) 43, 7954-65.

22. Schalk, I. J., Kyslik, P., Prome, D., van Dorsselaer, A., Poole, K., Abdallah, M. A., and Pattus, F. (1999) Copurification of the FpvA ferric pyoverdin receptor of Pseudomonas aeruginosa with its iron-free ligand: implications for siderophore-mediated iron transport. Biochemistry (Mosc.) 38, 9357-65.

23. Folschweiller, N., Gallay, J., Vincent, M., Abdallah, M. A., Pattus, F., and Schalk, I. J. (2002) The interaction between pyoverdin and its outer membrane receptor in Pseudomonas aeruginosa leads to different conformers: a time-resolved fluorescence study. Biochemistry (Mosc.) 41, 14591-601.

24. Stookey, L. L. (1970) Ferrozine-A New Spectrophotometric Reagent for Iron. Anal. Chem. 42, 779-781.

25. Xiao, R., and Kisaalita, W. S. (1998) Fluorescent pseudomonad pyoverdines bind and oxidize ferrous ion. Appl Env. Microbiol 64, 1472-6.

26. Albrechtgary, A. M., Blanc, S., Rochel, N., Ocaktan, A. Z., and Abdallah, M. A. (1994) 
Bacterial iron transport - coordination properties of pyoverdin Paa, a peptidic siderophore of Pseudomonas-aeruginosa. Inorg. Chem. 33, 6391-6402.

27. Hoegy, F., and Schalk, I. J. (2014) Monitoring iron uptake by siderophores. Methods Mol Biol 1149, 337-46.

28. Cunrath, O., Gasser, V., Hoegy, F., Reimmann, C., Guillon, L., and Schalk, I. J. (2015) A cell biological view of the siderophore pyochelin iron uptake pathway in Pseudomonas aeruginosa. Env. Microbiol 17, 171-85.

29. Stover, C. K., Pham, X. Q., Erwin, A. L., Mizoguchi, S. D., Warrener, P., Hickey, M. J., Brinkman, F. S., Hufnagle, W. O., Kowalik, D. J., Lagrou, M., Garber, R. L., Goltry, L., Tolentino, E., Westbrock-Wadman, S., Yuan, Y., Brody, L. L., Coulter, S. N., Folger, K. R., Kas, A., Larbig, K., Lim, R., Smith, K., Spencer, D., Wong, G. K., Wu, Z., Paulsen, I. T., Reizer, J., Saier, M. H., Hancock, R. E., Lory, S., and Olson, M. V. (2000) Complete genome sequence of Pseudomonas aeruginosa PAO1, an opportunistic pathogen. Nature 406, 959-64. 30. Shirley, M., and Lamont, I. L. (2009) Role of TonB1 in pyoverdine-mediated signaling in Pseudomonas aeruginosa. J Bacteriol 191, 5634-40.

31. Voisard, C., Bull, C., Keel, C., Laville, J., Maurhofer, M., Schnider, U., Défago, G., and Haas, D. (1994) Biocontrol of root diseases by Pseudomonas fluorescens CHAO: current concepts and experimental approaches, in Molecular Ecology of Rhizosphere Microorganisms (O’Gara, F., Dowling, D. N., and Boesten, Eds.), pp 67-89. VCH, Weinheim, Germany. 32. Morales, V. M., Backman, A., and Bagdasarian, M. (1991) A series of wide-host-range low-copy-number vectors that allow direct screening for recombinants. Gene 97, 39-47. 


\section{Pseudomonas aeruginosa}

$\mathrm{PAO} 1$
$\Delta p v d F$
$\Delta p v d F \Delta f p v A$
$\Delta p v d F \Delta f p v G$
$\Delta p v d F \Delta f p v G(\mathrm{pMMB} f p v G)$
$\Delta p v d F \Delta f p v H$
$\Delta p v d F \Delta f p v H(\mathrm{pMMB} f p v H)$
$\Delta p v d F \Delta f p v J$
$\Delta p v d F \Delta f p v K$
$\Delta p v d F \Delta f p v G H J K$
$\Delta p v d F \Delta f p v C$
$\Delta p v d F \Delta f p v D E$
$\Delta p v d F \Delta f p v F$
$\Delta p v d F \Delta f p v C D E F$

$\Delta p v d F \Delta \mathrm{fpvCDEF}(\mathrm{pMMB} f p v C D E F)$
PAO1

PAS047

PAS150

PAS279

PAS341

PAS280

PAS342

PAS281

PAS336

PAS337

PAS315

PAS317

PAS314

PAS318

PAS323

$\begin{array}{cc}\text { Wild-type strain } & 29 \\ \text { PAO1; } p v d F \text { chromosomally deleted } & 1 \\ \text { PAO1; } p v d F \text { and } f p v A \text { chromosomally } & 30\end{array}$
deleted

PAO1; $p v d F$ and $f p v G$ chromosomally This study deleted

Derivative of $\Delta p v d F \Delta f p v G$ transformed with $\mathrm{pMMB} f p v G$

PAO1; $p v d F$ and $f p v H$ chromosomally This study deleted

Derivative of $\Delta p v d \Delta f p v H$ transformed with pMMB $f p v H$

PAO1; $p v d F$ and $f p v J$ chromosomally This study deleted

PAO1; $p v d F$ and $f p v K$ chromosomally This study deleted

PAO1; $p v d F, f p v G, f p v H$, $f p v J$ and $f p v K \quad$ This study chromosomally deleted

PAO1; $p v d F$ and $f p v C$ chromosomally This study deleted

PAO1; $p v d F, f p v D$ and $f p v E$ chromosomally deleted

PAO1; $p v d F$ and $F p v F$ chromosomally This study deleted

PAO1; $p v d F, f p v C$, $f p v D, f p v E$ and $f p v F \quad$ This study chromosomally deleted

Derivative of PAO1

$\triangle p v d F \triangle f p v C D E F$ transformed with This study pMMB $f p v C D E F$

\section{Escherichia coli}

TOP 10

BL21(DE3) F- mcrA $\Delta$ (mrr-hsdRMS-mcrBC)
$\varphi 80$ lacZ $\Delta$ M15 $\Delta$ lacX74 nupG recA1

Invitrogen $\operatorname{araD139} \Delta$ (ara-leu) 7697 galE15 galK16 $\operatorname{rpsL}\left(\operatorname{Str}^{\mathrm{R}}\right)$ endA1 $\lambda^{-}$

\section{Plasmids}

pME3088

pMMB190

F-ompT hsdS $S_{B}\left(r_{B}-m_{B}{ }^{-}\right)$gal dcm $(\lambda$ DE3)

$\mathrm{pME} \Delta f p v G$

$\mathrm{pME} \Delta f p v H$

$\mathrm{pME} \Delta f p v J$
Suicide vector; TcR; ColE1 replicon; EcoRI KpnI DralI XhoI HindIII polylinker

Complementation vector; AmpR

pGG7

$\mathrm{pFH} 2$

pFH3
pME3088 carrying the sequence to delete fp $v G$

pME3088 carrying the sequence to delete $f p v H$

pME3088 carrying the sequence to delete fpv $J$
31

32

This study

This study

This study 


$$
\mathrm{pME} \Delta f p v K
$$

pME $\Delta f p v G H J K$

$\mathrm{pME} \Delta f p v C$

$\mathrm{pME} \Delta f p v D E$

$\mathrm{pME} \Delta f p v F$

pME $\triangle f p v C D E F$

$\mathrm{pMMB} f p v G$

pMMB $f p v H$

pET29a

pET29a(+)fpvGHis 6

${\text { pMMB190fp } v H \mathrm{His}_{6}}_{6}$

pMMB190His 6 fpvH

pET23a-789

pVEGA6

pET29a(+)-fpv $C_{m u t}$
pFH4

pGG8

pGG2

pGG3

pGG1

pLJ76

pGG10

pGG11

pET29a

pET29a(+)fpvGHis

pGG12

pGG13

pET23a-789

pVEGA6

$\mathrm{pET} 29 \mathrm{a}(+)-f p v C_{m u t}$
pME3088 carrying the sequence to delete fpvK

pME3088 carrying the sequence to delete fpvGHJK

pME3088 carrying the sequence to delete $f p v C$

pME3088 carrying the sequence to delete $f p v D E$

pME3088 carrying the sequence to delete $f p v F$

pME3088 carrying the sequence to delete fpvCDEF

pMMB190 carrying $f p v G$

pMMB190 carrying $f p v H$

vector carry an $\mathrm{N}$-terminal $\mathrm{S} \bullet \mathrm{Tag}^{\mathrm{TM}} /$ thrombin configuration plus a C-terminal His $\bullet$ Tag $^{\mathbb{B}}$ sequence pET29 carrying a C-terminal His-tagged This study $f p v G$

pMMB190 carrying a C-terminal Histagged $f p v H$

pMMB190 carrying a N-terminal Histagged $f p v H$

$$
\text { pET23 carrying } f p v C
$$

pMMB190 carrying EcoRI-HindIII

fragment containing $f p v F$-6His

pET29 carrying a C-terminal His-tagged This study $f p v C$ with the His $40,65,110,176,198$,
This study

This study

This study

This study

This study

20

This study

This study

Novagen

This study

This study

20

20 249 mutated into Gly

\section{Table 1: Strains and plasmids used in this study.}




\section{FIGURES WITH LEGENDS}

Figure 1: a) Organization of the PA2403-10 genes in the $P$. aeruginosa PAO1 genome. IMP, Inner Membrane Protein; PP, periplasmic protein; and PBP, periplasmic binding protein. See in Supporting information for the predicted membrane topology (Supplementary Figure 1).

b) Putative secondary structure of FpvG (PA2403). The black arrows show the $\beta$-sheets and the gray bars the $\alpha$-helices (light gray for the transmembrane regions).

c) Sequence of the periplasmic binding protein $\mathrm{FpvC}$ with a $\mathrm{C}$-terminal His tag. The His residues potentially involved in metal chelation ${ }^{20}$ and mutated into Gly in $\mathrm{FpvC}_{\mathrm{mut}}$ are shown in red.

Figure 2: a) ${ }^{55} \mathrm{Fe}$ uptake in $P$. aeruginosa strains after incubation with PVDI $-{ }^{55} \mathrm{Fe}$. $\Delta p v d F$, a PVDI-negative strain, and its corresponding deletion mutants $\Delta p v d F \Delta f p v G H J K$, $\Delta p v d F \Delta f p v G, \Delta p v d F \Delta f p v H, \Delta p v d F \Delta f p v J, \Delta p v d F \Delta f p v K$, as well as $\Delta p v d F \Delta f p v A$, its $f p v A$ deletion mutant (grown in CAA medium), were incubated with $200 \mathrm{nM}$ PVDI- ${ }^{55} \mathrm{Fe}$ for 15 or $30 \mathrm{~min}$. The cells were then pelleted and the radioactivity accumulated in the bacteria counted. The results are expressed as pmol of PVD- ${ }^{55} \mathrm{Fe}$ transported per $\mathrm{mL}$ of cells at an $\mathrm{OD}_{600 \mathrm{~nm}}$ of 1 . The error bars represent the standard deviations of the mean of three independent experiments.

b) ${ }^{55} \mathrm{Fe}$ repartition in the cell compartments of $P$. aeruginosa strains after incubation with PVDI- ${ }^{55}$ Fe. $\Delta p v d F$ and its corresponding deletion mutants $\Delta p v d F \Delta f p v A$, $\Delta p v d F \Delta f p v G H J K$, and $\Delta p v d F \Delta f p v G$, were first grown in CAA medium and then incubated with $200 \mathrm{nM}$ PVDI- ${ }^{55} \mathrm{Fe}$ for $30 \mathrm{~min}$. The cells were then pelleted, the periplasm, cytoplasm and membrane fractions isolated for each strain as described in Materials and Methods, and 
the amount of ${ }^{55} \mathrm{Fe}$ present measured. The results are expressed as the percentage of pmol of

${ }^{55} \mathrm{Fe}$ incubated with the strains. The errors bars represent the standard deviation of the mean of three independent experiments.

Figure 3: a and b) In vivo PVDI-Fe dissociation kinetics, measured by direct excitation of PVDI. Cells $(\Delta p v d F, \quad \Delta p v d F \Delta f p v G, \quad \Delta p v d F \Delta f p v H, \quad \Delta p v d F \Delta f p v J, \quad \Delta p v d F \Delta f p v K$, $\Delta p v d F \Delta f p v G H J K$, and $\Delta p v d F \Delta f p v A$ cells for panel $\mathrm{A}$ and $\Delta p v d F, \Delta p v d F \Delta f p v C$, $\Delta p v d F \Delta f p v D E, \Delta p v d F \Delta f p v F, \Delta p v d F \Delta f p v C D E F$, and $\Delta p v d F \Delta f p v A$ for panel B) were washed and resuspended to an $\mathrm{OD}_{600 \mathrm{~nm}}$ of 0.4 in $50 \mathrm{mM}$ Tris- $\mathrm{HCl}, \mathrm{pH} 8.0$, and incubated at $30^{\circ} \mathrm{C}$. The change in PVDI fluorescence (excitation set at $400 \mathrm{~nm}$ ) was monitored by measuring the emission of fluorescence at $447 \mathrm{~nm}$, every $300 \mathrm{~ms}$, for $60 \mathrm{~min}$, in a TECAN microplate reader. After 10 min, $120 \mathrm{nM}$ PVDI-Fe was added as indicated by the black vertical line. The kinetics experiments were repeated in the absence of PVDI-Fe for all strains tested and no increase of fluorescence was observed (data not shown).

c and d) PVDI recycling after iron uptake measured by fluorescence. Bacterial cells $(\Delta p v d F, \Delta p v d F \Delta f p v G, \Delta p v d F \Delta f p v H, \Delta p v d F \Delta f p v J, \Delta p v d F \Delta f p v K, \Delta p v d F \Delta f p v G H J K$, and $\Delta p v d F \Delta f p v A$ cells for panel $\mathrm{C}$ and $\Delta p v d F, \Delta p v d F \Delta f p v C, \Delta p v d F \Delta f p v D E, \Delta p v d F \Delta f p v F$, $\Delta p v d F \Delta f p v C D E F$, and $\Delta p v d F \Delta f p v A$ for panel D) were incubated to an $\mathrm{OD}_{600 \mathrm{~nm}}$ of 1 in 50 $\mathrm{mM}$ Tris- $\mathrm{HCl}(\mathrm{pH} 8.0)$ buffer in the presence of $120 \mathrm{nM}$ PVDI-Fe at $30^{\circ} \mathrm{C}$. Aliquots $(200 \mu \mathrm{L})$ were collected at intervals, the cells removed by centrifugation, and the fluorescence in 150 $\mu \mathrm{L}$ supernatant measured at $447 \mathrm{~nm}\left(\lambda_{\text {ext }}=400 \mathrm{~nm}\right)$ using a TECAN microplate reader. The experiment was repeated for all strains in the absence of PVDI-Fe addition (data not shown) and no time-dependent increase of fluorescence was observed.

All the kinetics experiments presented in panels A-D were performed three times and equivalent kinetics were observed. 
Figure 4: Dissociation of PVDI-Fe in vitro. For all shown experiments, $20 \mu \mathrm{M}$ PVDI-Fe was incubated in $100 \mathrm{mM}$ ammonium acetate buffer $(\mathrm{pH}$ 6.5) in the absence or presence of $100 \mathrm{mM}$ DTT, $100 \mathrm{mM}$ ascorbic acid, $200 \mu \mathrm{M}$ ferrozine, $10 \mu \mathrm{M}$ FpvC, $10 \mu \mathrm{M} \mathrm{FpvF,} 10 \mu \mathrm{g}$ membranes of BL21(DE3) or BL21(DE3)(pET29a(+)FpvGHis 6 ) cells overexpressing FpvG. For panel D, ferrozine was added to $20 \mu \mathrm{M}$ (1 equivalent compared to the PVDI-Fe concentration), $200 \mu \mathrm{M}$ (10 eq.), or $2 \mathrm{mM}$ (100 eq.). For all experiments, the change in fluorescence (excitation set at $400 \mathrm{~nm}$ ) was monitored by measuring the emission of fluorescence at $447 \mathrm{~nm}$, every second, for $60 \mathrm{~min}$. For panel A, the kinetics shown by the solid lines were measured by emission of fluorescence at $447 \mathrm{~nm}$ and those shown by the dotted lines by absorbance at $562 \mathrm{~nm} . \mathrm{F}_{0}=$ fluorescence at time $\mathrm{t}_{0}$ and $\mathrm{F}=$ fluorescence at time $\mathrm{t}, \mathrm{A}_{0}=$ absorbance at time $\mathrm{t}_{0}$ and $\mathrm{A}=$ absorbance at time $\mathrm{t}$. The various compounds added for each experiment are specified on the different panels with the corresponding colors, except for several curves corresponding to controls in panel A: gray curve, $100 \mathrm{mM}$ ammonium acetate buffer ( $\mathrm{pH}$ 6.5) alone; dark gray curve, PVDI-Fe alone; black curve, DTT alone; brown curve, ferrozine alone; khaki curve, DTT incubated with ferrozine alone (no PVDI-Fe).

Figure 5: Western blot analyses of membranes of BL21(DE3) E. coli cells expressing FpvG. The membranes were prepared as described in Materials and Methods and $15 \mu \mathrm{g}$ of proteins were loaded for each lane. Lane 2, soluble (cytoplasm and periplasm) fraction; lane 3: membrane fraction. His tagged FpvG (MW of $45.9 \mathrm{kDa}$ ) was detected using a rabbit antiHis monoclonal antibody (GeneTex). 
Figure 1: a) Organization of the PA2403-10 genes in the P. aeruginosa PAO1 genome. IMP, Inner Membrane Protein; PP, periplasmic protein; and PBP, periplasmic binding protein. See in Supporting information for the predicted membrane topology (Supplementary Figure 1).

b) Putative secondary structure of FpvG (PA2403). The black arrows show the $\beta$-sheets and the gray bars the a-helices (light gray for the transmembrane regions).

c) Sequence of the periplasmic binding protein FpvC with a C-terminal His tag. The His residues potentially involved in metal chelation 20 and mutated into Gly in FpvCmut are shown in red.

Figure 1

$104 \times 78 \mathrm{~mm}(300 \times 300$ DPI $)$ 

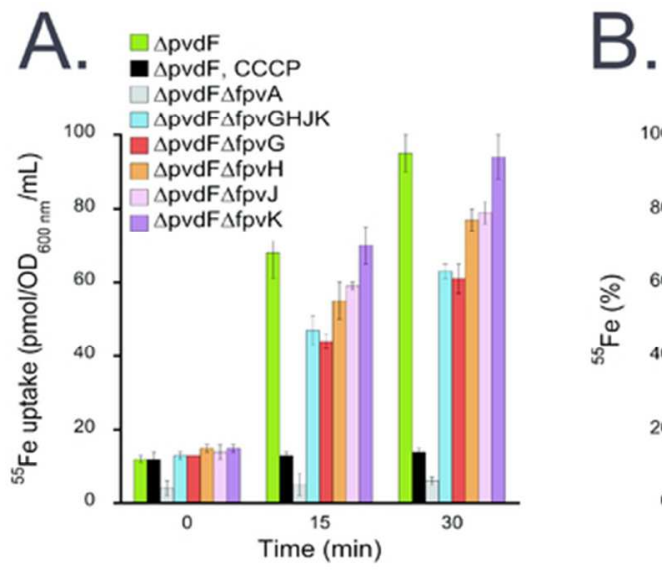

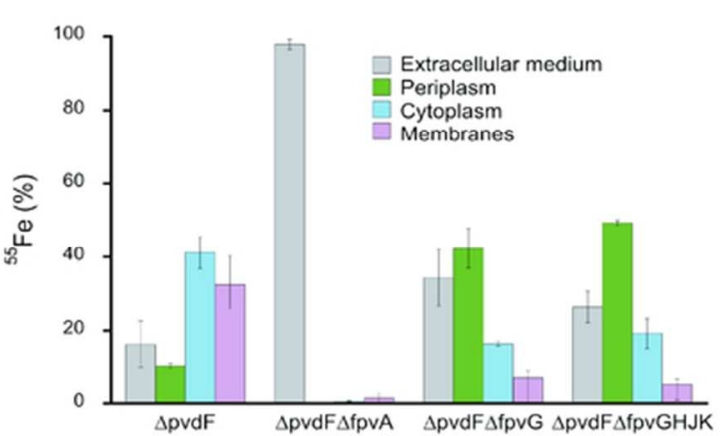

Figure 2: a) 55Fe uptake in P. aeruginosa strains after incubation with PVDI-55Fe. $\Delta$ pvdF, a PVDI-negative strain, and its corresponding deletion mutants $\Delta$ pvdF $\Delta \mathrm{fpvGHJK}, \Delta \mathrm{pvdF} \Delta \mathrm{fpvG}, \Delta \mathrm{pvdF} \Delta \mathrm{fpvH}, \Delta \mathrm{pvdF} \Delta \mathrm{fpv}$, $\triangle \mathrm{pvdF} \Delta \mathrm{fpvK}$, as well as $\triangle \mathrm{pvdF} \Delta \mathrm{fpvA}$, its fpvA deletion mutant (grown in CAA medium), were incubated with $200 \mathrm{nM}$ PVDI-55Fe for 15 or $30 \mathrm{~min}$. The cells were then pelleted and the radioactivity accumulated in the bacteria counted. The results are expressed as pmol of PVD-55Fe transported per mL of cells at an OD600 $\mathrm{nm}$ of 1 . The error bars represent the standard deviations of the mean of three independent experiments. b) $55 F e$ repartition in the cell compartments of $P$. aeruginosa strains after incubation with PVDI-55Fe. $\triangle$ pvdF and its corresponding deletion mutants $\triangle \mathrm{pvdF} \Delta \mathrm{fpvA}, \triangle \mathrm{pvdF} \Delta \mathrm{fpvGHJK}$, and $\Delta \mathrm{pvdF} \Delta \mathrm{fpvG}$, were first grown in

CAA medium and then incubated with $200 \mathrm{nM}$ PVDI-55Fe for $30 \mathrm{~min}$. The cells were then pelleted, the periplasm, cytoplasm and membrane fractions isolated for each strain as described in Materials and Methods, and the amount of 55Fe present measured. The results are expressed as the percentage of pmol of $55 \mathrm{Fe}$ incubated with the strains. The errors bars represent the standard deviation of the mean of three independent experiments.

Figure 2

$61 \times 27 \mathrm{~mm}(300 \times 300 \mathrm{DPI})$ 

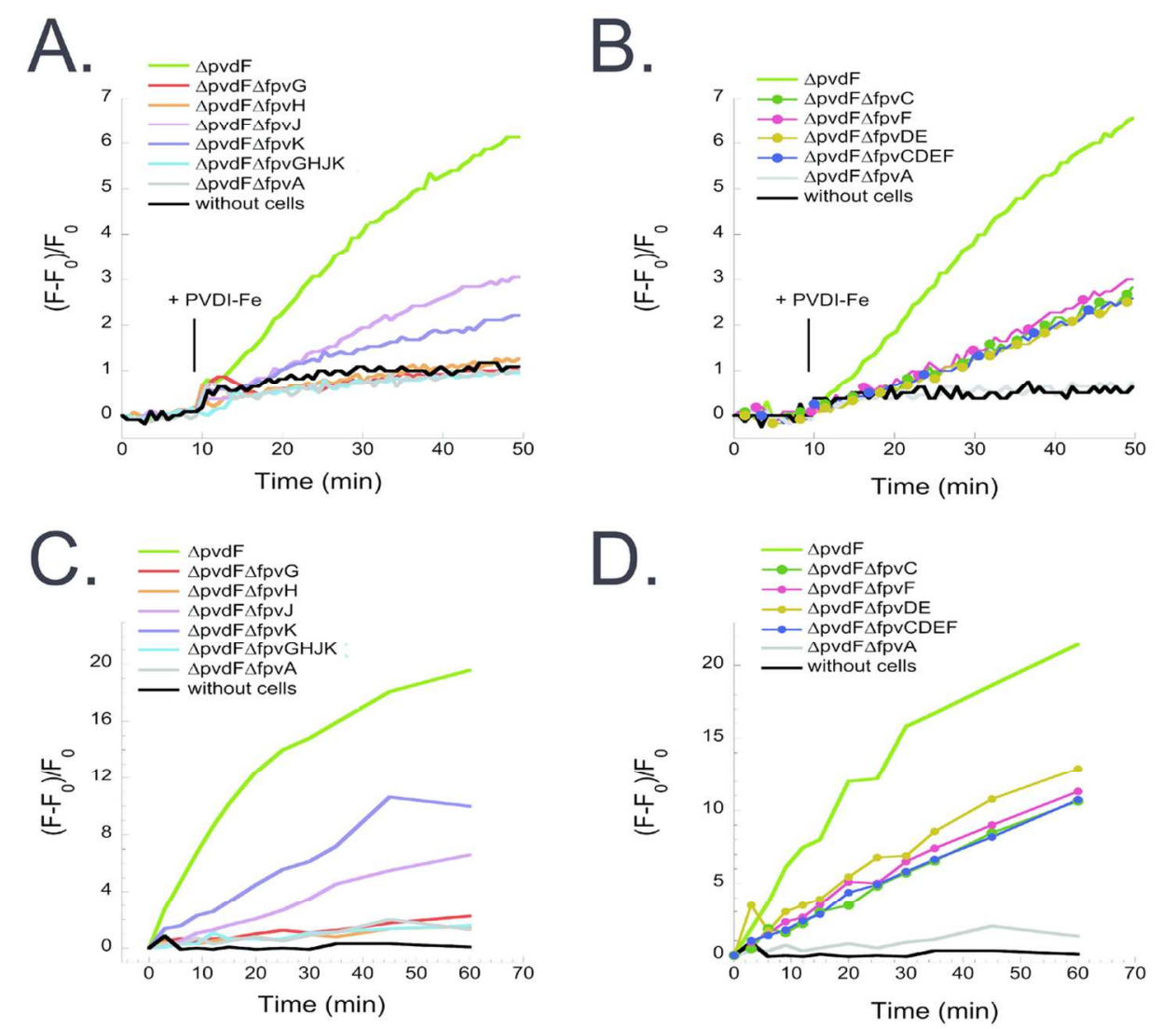

Figure 3: $a$ and $b$ ) In vivo PVDI-Fe dissociation kinetics, measured by direct excitation of PVDI. Cells ( $\triangle$ pvdF, $\Delta$ pvdF $\Delta$ fpvG,$\Delta$ pvdF $\Delta \mathrm{fpvH}, \Delta$ pvdF $\Delta \mathrm{fpv}, \Delta \mathrm{pvdF} \Delta \mathrm{fpvK}, \Delta \mathrm{pvdF} \Delta \mathrm{fpvGHJK}$, and $\Delta \mathrm{pvdF} \Delta \mathrm{fpvA}$ cells for panel $A$ and $\Delta \mathrm{pvdF}, \Delta \mathrm{pvdF} \Delta \mathrm{fpvC}, \Delta \mathrm{pvdF} \Delta \mathrm{fpvDE}, \Delta \mathrm{pvdF} \Delta \mathrm{fpvF}, \Delta \mathrm{pvdF} \Delta \mathrm{fpvCDEF}$, and $\Delta \mathrm{pvdF} \Delta \mathrm{fpvA}$ for panel B) were washed and resuspended to an OD600 nm of 0.4 in $50 \mathrm{mM}$ Tris- $\mathrm{HCl}, \mathrm{pH} 8.0$, and incubated at $30^{\circ} \mathrm{C}$. The change in PVDI fluorescence (excitation set at $400 \mathrm{~nm}$ ) was monitored by measuring the emission of fluorescence at $447 \mathrm{~nm}$, every $300 \mathrm{~ms}$, for $60 \mathrm{~min}$, in a TECAN microplate reader. After $10 \mathrm{~min}, 120 \mathrm{nM}$ PVDI-Fe was added as indicated by the black vertical line. The kinetics experiments were repeated in the absence of PVDI-Fe for all strains tested and no increase of fluorescence was observed (data not shown). $\mathrm{c}$ and d) PVDI recycling after iron uptake measured by fluorescence. Bacterial cells ( $\Delta \mathrm{pvdF}, \Delta \mathrm{pvdF} \Delta \mathrm{fpvG}$, $\Delta \mathrm{pvdF} \Delta \mathrm{fpvH}, \Delta \mathrm{pvdF} \Delta \mathrm{fpvJ}, \Delta \mathrm{pvdF} \Delta \mathrm{fpvK}, \Delta \mathrm{pvdF} \Delta \mathrm{fpvGHJK}$, and $\Delta \mathrm{pvdF} \Delta \mathrm{fpvA}$ cells for panel $\mathrm{C}$ and $\Delta \mathrm{pvdF}$, $\Delta \mathrm{pvdF} \Delta \mathrm{fpvC}, \Delta \mathrm{pvdF} \Delta \mathrm{fpvDE}, \Delta \mathrm{pvdF} \Delta \mathrm{fpvF}, \Delta \mathrm{pvdF} \Delta \mathrm{fpvCDEF}$, and $\triangle \mathrm{pvdF} \Delta \mathrm{fpvA}$ for panel D) were incubated to an OD600 nm of 1 in $50 \mathrm{mM}$ Tris- $\mathrm{HCl}\left(\mathrm{pH} \mathrm{8.0)}\right.$ buffer in the presence of $120 \mathrm{nM}$ PVDI-Fe at $30^{\circ} \mathrm{C}$. Aliquots $(200 \mu \mathrm{L})$ were collected at intervals, the cells removed by centrifugation, and the fluorescence in $150 \mu \mathrm{L}$ supernatant measured at $447 \mathrm{~nm}(\lambda$ ext $=400 \mathrm{~nm})$ using a TECAN microplate reader. The experiment was repeated for all strains in the absence of PVDI-Fe addition (data not shown) and no time-dependent increase of fluorescence was observed.

All the kinetics experiments presented in panels A-D were performed three times and equivalent kinetics were observed.

Figure 3

$119 \times 101 \mathrm{~mm}(300 \times 300$ DPI $)$ 

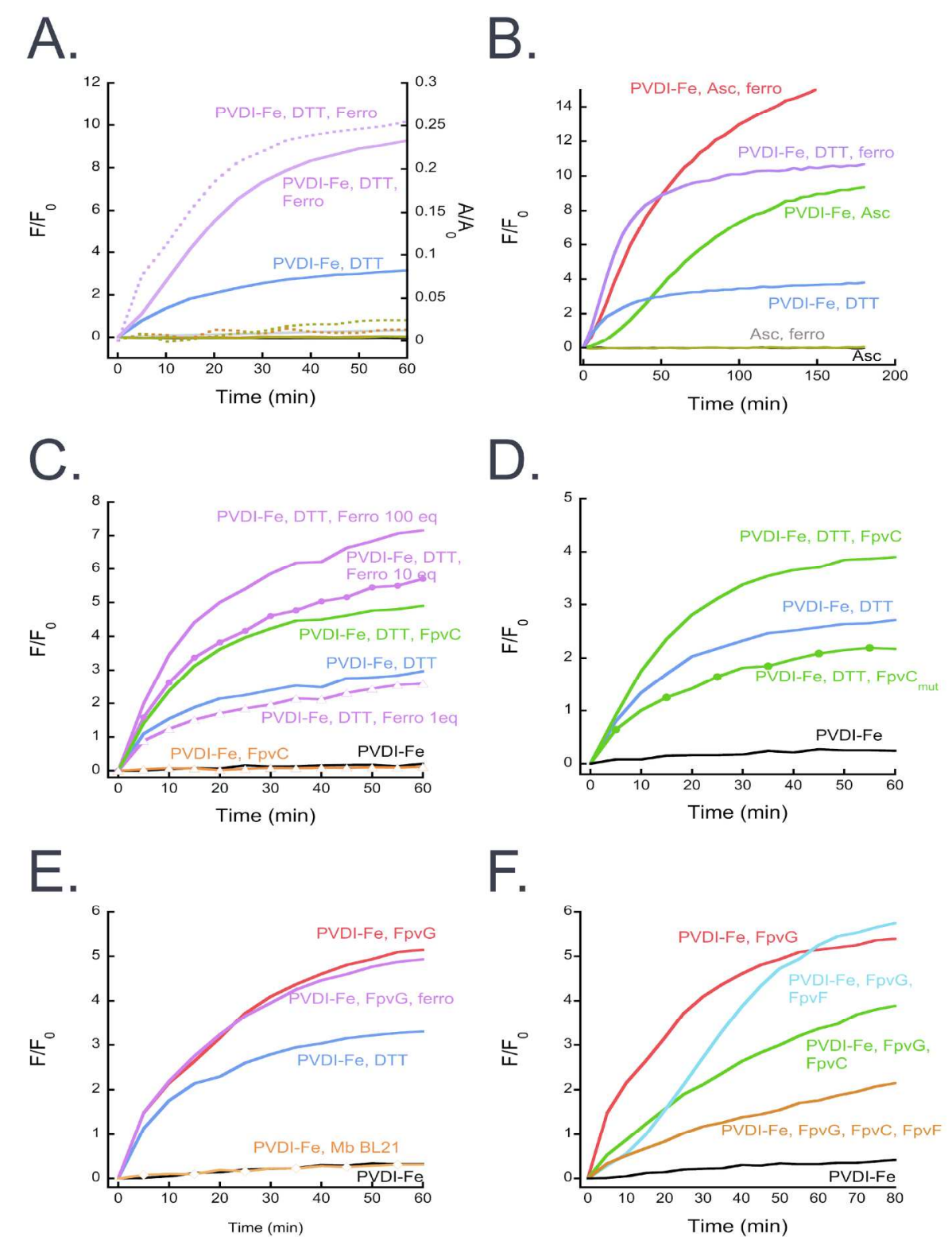

F.

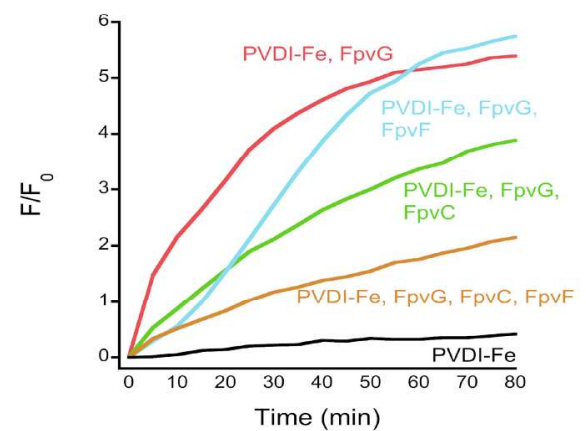

Figure 4: Dissociation of PVDI-Fe in vitro. For all shown experiments, $20 \mu \mathrm{M}$ PVDI-Fe was incubated in 100 $\mathrm{mM}$ ammonium acetate buffer ( $\mathrm{pH} 6.5)$ in the absence or presence of $100 \mathrm{mM}$ DTT, $100 \mathrm{mM}$ ascorbic acid, $200 \mu \mathrm{M}$ ferrozine, $10 \mu \mathrm{M} \mathrm{FpvC,} 10 \mu \mathrm{M} \mathrm{FpvF}, 10 \mu \mathrm{g}$ membranes of BL21(DE3) or BL21(DE3)(pET29a(+)FpvGHis6) cells overexpressing FpvG. For panel D, ferrozine was added to $20 \mu \mathrm{M}$ (1 equivalent compared to the PVDI-Fe concentration), $200 \mu \mathrm{M}$ (10 eq.), or $2 \mathrm{mM}$ (100 eq.). For all experiments, the change in fluorescence (excitation set at $400 \mathrm{~nm}$ ) was monitored by measuring the emission of fluorescence at $447 \mathrm{~nm}$, every second, for $60 \mathrm{~min}$. For panel $\mathrm{A}$, the kinetics shown by the solid lines were measured by emission of fluorescence at $447 \mathrm{~nm}$ and those shown by the dotted lines by absorbance at $562 \mathrm{~nm}$. FO = fluorescence at time t0 and $\mathrm{F}=$ fluorescence at time $\mathrm{t}, \mathrm{A} 0=$ absorbance at time to and $A=$ absorbance at time $t$. The various compounds added for each experiment are specified on the different panels with the corresponding colors, except for several curves corresponding to controls in panel A: gray curve, $100 \mathrm{mM}$ ammonium acetate buffer ( $\mathrm{pH}$ 6.5) alone; dark gray curve, PVDI-Fe alone; black curve, DTT alone; brown curve, ferrozine alone; khaki curve, DTT incubated with ferrozine alone (no 


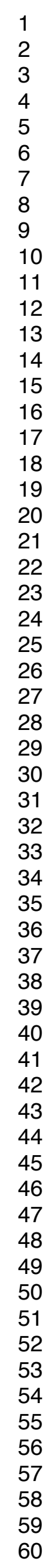

PVDI-Fe).

Figure 4

$183 \times 241 \mathrm{~mm}(300 \times 300 \mathrm{DPI})$

14

15

16

18

19

20

22

23

25

26

27

29

30

33

34

35

36

39

40

41

42

44

45

46

47

48

50

51

52

54

55 
Figure 5: Western blot analyses of membranes of BL21(DE3) E. coli cells expressing FpvG. The membranes were prepared as described in Materials and Methods and $15 \mu \mathrm{g}$ of proteins were loaded for each lane. Lane 2, soluble (cytoplasm and periplasm) fraction; lane 3: membrane fraction. His tagged FpvG (MW of 45.9 $\mathrm{kDa}$ ) was detected using a rabbit anti-His monoclonal antibody (GeneTex).

Figure 5

$73 \times 79 \mathrm{~mm}(300 \times 300 \mathrm{DPI})$ 
Fe dissociation from siderophore pyoverdine in $P$. aeruginosa periplasm

\author{
Graphical abstract \\ $44 \times 25 \mathrm{~mm}(300 \times 300 \mathrm{DPI})$
}

